\title{
Dominance rank and self-scratching among wild female Barbary macaques
}

\section{(Macaca sylvanus)}

\author{
Stefano S. K. Kaburu ${ }^{1,2 *}$, Ann MacLarnon ${ }^{1}$, Bonaventura Majolo ${ }^{3}$, Mohamed Qarro ${ }^{4}$, Stuart \\ Semple $^{1}$
}

${ }^{1}$ Centre for Research in Evolutionary and Environmental Anthropology, University of Roehampton, London SW15 4JD, UK.

${ }^{2}$ School of Anthropology and Conservation, Department of Anthropology, University of Kent, Kent CT2 7NR, U.K.

${ }^{3}$ School of Psychology, University of Lincoln, Brayford Pool, Lincoln, LN6 7TS, UK.

${ }^{4}$ Ecole Nationale Forestiére d'Ingénieurs. Avenue Moulay Yousseff, BP 511, Tabriquet, 1100 Salé, Morocco.

Measuring rates of self-scratching provides a powerful index of anxiety in non-human primates, and investigating the relationship between self-scratching and dominance rank can shed light on the 'emotional costs' of holding different positions in the hierarchy. Here we explored the relationship between self-scratching rates and rank in wild adult female Barbary macaques (Macaca sylvanus) in Morocco. We found a significant correlation between rank and females' mean self-scratching rates over the study period, with subordinates showing higher rates of self-scratching. Analysis of temporal variation in females' self-scratching rates indicated that while these rates were related to measures of both grooming and aggression, the relationship between rank and self-scratching remained significant even after controlling for these effects. Our data suggest that lower ranked female Barbary macaques suffer higher levels of anxiety than more dominant individuals, and hence that there is an emotional cost associated with having low social status in this species.

Keywords: Barbary macaque, rank, anxiety, self-scratching, aggression, grooming

*Author for correspondence

Email:sskk2@kent.ac.uk 


\section{INTRODUCTION}

Understanding how social status affects emotional state has been a key goal for scientists studying both humans (e.g. Tiedens 2000) and non-human animals (e.g. Pavani et al. 1991). Accessing the emotional states of non-human animals is, of course, difficult as they lack the language faculty with which to communicate these states (Paul et al. 2005). However, behavioural measures can provide a proxy index of emotion (Maestripieri et al. 1992a). Among non-human primates, pharmacological studies provide evidence that measuring rates of self-directed behaviours, particularly selfscratching, can provide an index of one particular emotion: anxiety. Schino et al. (1991) found that when female long tailed macaques (Macaca fascicularis) were given Lorazepam, a drug that in humans reduces anxiety, rates of self-scratching decreased, particularly among lower ranked females. Working with male long tailed macaques, Schino et al. (1996) found that combined rates of self-directed behaviours (including self-scratching) decreased when the animals were given Lorazepam, and increased when the anxiety inducing drug FG 7142 was given; these changes were dose related i.e. the greater the drug dose, the bigger the change in self-directed behaviour. Similarly, infant rhesus macaques (M. mulatta) treated with the anxiogenic B-CCE showed a tendency for increased rates of self-scratching, while those treated with the anxiolytic midazolam showed a tendency for reduced self-scratching rates (Maestripieri et al. 1992b). Finally, Redmond \& Huang (1979) found that electrical and pharmacological stimulation of the locus coeruleus, a brain region involved in anxiety, increased the frequency of self-scratching among stump-tailed macaques (M. arctoides).

Primatologists working on a broad range of species have quantified rates of self-scratching in order to investigate how anxiety levels vary according to individuals' position in the dominance hierarchy; findings have varied markedly across the species investigated. Low ranked animals selfscratch more than high ranked ones in wild brown lemurs (Eulemur fulvus: Palagi \& Norscia 2010) and captive long-tailed macaques (Pavani et al. 1991). By contrast, high ranked captive male olive baboons (Papio cynocephalus anubis) exhibit higher rates of self-scratching than low ranked males 
(Easley et al. 1987), and high ranked captive female mandrills (Mandrillus sphinx) scratch themselves more than low ranked females (Peignot et al. 2004). Diezinger \& Anderson (1986) found that baseline self-scratching rates did not differ between high, middle and low ranked adult rhesus macaques but that rank-related differences did emerge at certain times; during feeding times, for example, mid-ranked animals showed greater elevations of self-scratching than did low or high ranked animals. Finally, Daniel et al.(2009) found no relationship between rank and self-scratching in captive vervets, Chlorocebus aethiops.

The variation among primate species in the relationship between rank and self-scratching is intriguing, and data on further species are needed to help identify the factors underlying these differences. Moreover, it is unclear from studies of this kind whether associations between selfscratching rate and rank reflect the fact that holding different positions in the hierarchy per se causes different levels of anxiety, or whether this relationship is confounded by rank-related behaviours, in particular aggression and grooming. There is evidence from a range of primate species that aggression elevates self-scratching in both the victim and the aggressor (e.g. Bonnet macaques, M. radiata: Cooper et al. 2007; Japanese macaques, M. fuscata: Schino et al. 2007). Similarly, both the giving (crested macaques: M. nigra: Aureli and Yates, 2009) and the receiving (long-tailed macaques: Schino et al 1988) of grooming have been linked to a reduction in rates of self-scratching. Exploring the relationship between rank and self-scratching, while controlling for the potentially confounding effect of variation in rates of aggression and grooming, will provide further insight into the 'emotional costs' of holding different social positions.

In this study, we investigate the relationship between dominance rank and self-scratching among wild adult female Barbary macaques (Macaca sylvanus). We quantify the linearity and steepness of the female dominance hierarchy, the first time these parameters have been quantified in the wild for this species. Next, we investigate the association between dominance rank and females' mean self-scratching rates over the study period. Finally, we use a generalised linear mixed model (GLMM) approach to analyse temporal variation in self-scratching rates, in order to investigate 
whether rank and rates of self-scratching are related after controlling for rates of aggression and grooming.

\section{METHODS}

\section{Study site and group}

Fieldwork was carried out by S.S.K.K. between February and May 2009 in the Middle Atlas Mountains of Morocco. The study site $\left(33^{\circ} 24^{\circ} \mathrm{N}-005^{\circ} 12^{\prime} \mathrm{W}\right)$ is situated close to the city of Azrou, at 1700-2000 m above sea level. The study group (Green group) consisted of 23 individuals: 11 males ( 8 adults and 3 sub-adults), seven females ( 6 adults and 1 sub-adult), two juvenile males and three infants. This research focused on all the females of the group $\geq 4$ years old; five out of these seven females gave birth during the observation period. Preliminary analyses found that reproductive state did not affect self-scratching rates (Kaburu 2009) so this variable was not included in analyses.

\section{Behavioural data}

The group was monitored for approximately nine hours per day (from 08.00 to 17.00), five days per week. This gave us a total of 153 observation hours (range: 19h 52m - 23h 44m per female). Data were collected during 30-minute focal watches (Altmann 1974). All occurrences of selfscratching by the focal animal were recorded, as were the occurrence and direction of all events of aggression (slap, grab, bite, jump on and chase, lunge, charge, ground slap, stare and open mouth threat) involving the focal, along with the identity of the other animal involved. When a selfscratching session was interrupted for longer than $5 \mathrm{~s}$, the subsequent self-scratching event was considered as a new bout. During grooming bouts involving the focal animal, the duration of the grooming bout, the identity of the partner and the direction of grooming were recorded. In cases when the focal animal was lost or there was disturbance (e.g. from tourists or local shepherds), we discarded data from sessions lasting less than 20 minutes. The order of focal animals was randomized prior to data collection. We also collected ad libitum data on dyadic aggressive 
encounters involving adult females; these data were combined with data from focal watches to construct the dominance hierarchy but were not used to calculate aggression rates.

\section{Analysis}

The linearity of the hierarchy was assessed using MatMan (de Vries et al. 1993). To explore hierarchy steepness, we used R (R Development Core Team, 2010) to calculate the Normalized David Scores (NormDS), taking into account the variation in interaction frequencies, $\mathrm{D}_{\mathrm{iJ}}$ (de Vries 1998; de Vries et al. 2006). The least-squares linear regression of NormDS was plotted according to descending rank order to calculate steepness (de Vries et al. 2006).

Mean rates of self-scratching over the entire study period were calculated for each female, and Spearman's rank correlation test used to determine if these rates were correlated with dominance rank. Next, we used Generalised Linear Mixed Models (GLMM) in MLWin to assess whether temporal variation in self-scratching rates was predicted by rank, focal females' rates of grooming given and received to/from both sexes and rates of aggression given to other adult females and received from adults of both sexes (females were never observed directing aggression towards adult males). As individuals were sampled repeatedly, we used a repeated measures model, with days (level 1, N=40) nested within individual (level 2, N =7), as random effects. All statistical tests were two tailed, with $\alpha=0.05$.

\section{RESULTS \& DISCUSSION}

Females showed a perfectly linear dominance hierarchy with no reversals $\left(\mathrm{h}_{1}=1, \mathrm{Kr}=1, \mathrm{DC}=1\right.$, $\mathrm{p}=0.0028$; Table 1), which is consistent with what has been reported in other wild communities of Barbary macaques (Deag, 1977; Taub, 1980). The female hierarchy showed a steepness of 0.96 $(\mathrm{p}<0.001)$. Data on steepness of hierarchies in this and other macaque species are typically available only for captive or provisioned populations (Schino \& Aureli 2008), and show high inter-and intra species variation in steepness (Macaca arctoides: 0.89-1.00; M. fascicularis: 0.67-0.84; M. fuscata: 0.07-0.99; M. radiata: 0.95; M. sylvanus: 0.91, Schino \& Aureli 2008). While further data on wild, 
unprovisioned groups are needed in order to provide the most appropriate comparative context in which to interpret our findings for Barbary macaques, it is notable that the steepness value found in the current study (0.96) is close to the maximum possible value of 1.0.

Females' mean self-scratching rates over the study period ranged from $2.78 / \mathrm{hr}$ to $8.71 / \mathrm{hr}$, with an overall mean rate across females of $6.09 / \mathrm{hr}$. A positive and significant correlation was found between rank and mean rates of self-scratching (Spearman' rank correlation, $\mathrm{N}=7, \mathrm{r}_{\mathrm{s}}=0.829, \mathrm{p}=$ 0.021; Figure 1), with lower-ranking females scratching at higher rates. The GLMM analysis revealed that self-scratching rates were positively related to rates of aggression given to adult females, aggression received from adult males and grooming given to adult males, and were negatively related to rates of grooming received from adult males; however, the positive relationship between rank and self-scratching remained significant after controlling for these effects (Table 2).

Overall, these findings suggest that lower ranked adult female Barbary macaques suffer higher levels of anxiety than higher ranked individuals, highlighting a potentially important cost of subordinate status in this species.

Our results add to a growing dataset linking average rates of self-scratching to dominance rank. To our knowledge, however, this is only the second published study to explore this relationship in the wild (see also Palagi \& Norscia 2010), and is the first to do so while controlling for variation in rates of key behaviours that may affect anxiety levels: aggression and grooming. Data such as these from natural settings are particularly valuable as they allow exploration of the link between social status and self-scratching within the environment in which the animals evolved. The captive environment is likely to have a large effect on animals' anxiety levels, and indeed comparison of our study animals' mean self-scratching rates with those seen in a captive study of the same species support this idea. In a study of Barbary macaques at Apenheul Zoo, Aureli (1997) found mean rates of self-scratching of $17.1 / \mathrm{hr}$, which is almost three times higher than the mean of females' levels in this study (6.09/hr). Data on self-scratching rates and rank, collected in the wild from a broader 
range of species, will ultimately facilitate comparative analyses investigating the factors underpinning inter-specific variation in how these parameters may be related. Ideally, such studies would also collect data on other parameters - unrelated to anxiety - that may affect self-scratching rates, such as ectoparasite load and weather conditions (Ventura et al. 2005).

The evidence found here that the giving and receiving of aggression increase rates of selfscratching, while the receipt of grooming lowers these rates, is in line with findings of previous studies (aggression: Cooper et al. 2007; Schino et al. 2007; grooming: Schino et al. 1988).

However, such effects in the current study were related to the sex of the social partner; for example, receiving grooming from males was associated with lower self-scratching rates, but receiving grooming from females was not. This suggests that future studies should consider not just the way in which positive and negative social behaviours affect anxiety levels, but also how the sex of the other animal involved in the interaction may mediate this effect. Surprisingly we found that selfscratching rates were positively related to the amount of grooming females gave to adult males. This result is hard to interpret, but may reflect the fact that approaching larger, more powerful adult males (as is required for grooming them) causes females anxiety.

Our finding that self-scratching rates of lower ranked females were still higher after controlling for the potentially confounding effects of aggression and grooming suggests that there is something about holding a low position in the hierarchy, other than increased involvement in aggression or reduced participation in grooming, that causes anxiety. One possibility is that for lower ranked females there are more animals in the group that outrank them, and the mere proximity of these higher ranked animals is anxiogenic. The effects of conspecific proximity on increasing selfscratching rates are well documented (e.g. Castles et al. 1999; Kutsukake 2003). Further studies of the interactions between rank, self-scratching, behaviour and spatial association will shed light on the factors underlying variation in anxiety levels among individuals in primate social groups.

\section{Acknowledgments}


We thank the Haut Commissariat aux Eaux et Forêts et à la Lutte Contre la Désertification of Morocco for research permission to conduct this study. We thank Richard McFarland, Abderrahmane Rakkas and Itto Fenani for their logistical support in the field, Elham-Maria Mahfouz for her help during data collection, David Leiva for providing us with the package to calculate hierarchy steepness and Peter Shaw, Lauren Brent and Charlotte Carne for statistical advice. We also thank two anonymous referees for their comments on a previous version of the manuscript. A grant from the Leakey Trust to S.S.K.K. assisted with field expenses.

\section{REFERENCES}

ALTMANN, J. 1974 . Observational study of behaviour sampling methods. Behaviour 49: 227-265. AURELI, F.1997. Post-conflict anxiety in nonhuman primates: The mediating role of emotion in conflict resolution. Aggressive Behavior 23:315-328.

AURELI, F., PRESTON, S. \& DE WAAL, F.B.M. 1999. Heart rate responses to social interactions in free-moving rhesus macaques (Macaca mulatta): a pilot study. Journal of Comparative Psychology 113: 59-65.

AURELI, F., CORDS, M. \& VAN SCHAIK, C.P. 2002. Conflict resolution following aggression in gregarious animals: a predictive framework. Animal Behaviour 64: 325-343.

AURELI, F. \& YATES, K. 2010. Distress prevention by grooming others in crested black macaques. Biology Letters 23: 27-9.

BOCCIA, M.L., REITE, M. \& LAUDENSLAGER, M. 1989. On the physiology of grooming in a pigtail macaque. Physiology \& Behaviour 45: 667-670.

CASTLES, D.L., WHITEN, A. \& AURELI, F. 1999. Social anxiety, relationships and self-directed behaviour among wild female olive baboons. Animal Behaviour 58: 1207-1215.

COOPER, M.A., AURELI, F. \& SINGH, M. 2007. Sex differences in reconciliation and postconflict anxiety in bonnet macaques. Ethology 113: 26-38.

DANIEL, J.R., DOS SANTOS, A.J. \& VINCENT, L. 2009. Correlates of self-directed behaviors in 
captive Cercopithecus aethiops. International Journal of Primatology 29: 1219-1226.

DEAG, J.M. (1977). Aggression and submission in monkey societies. Animal Behaviour 25: 465474.

DE VRIES, H. 1998.Finding a dominance order most consistent with a linear hierarchy: a new procedure and review. Animal Behaviour 55: 827-843.

DE VRIES, H., NETTO, W.J. \& HANEGRAAF, P.L.H. 1993. MatMan: A program for the analysis of sociometric matrices and behavioural transition matrices. Behaviour 125: 157-175.

DE VRIES, H. STEVENS, J.M.G. \& VERVAECKE, H. 2006. Measuring and testing the steepness of dominance hierarchies. Animal Behaviour 71: 585-592.

DIEZINGER, F. \& ANDERSON, D.J.R. 1986. Starting from scratch: A first look at a displacement activity in group-living rhesus monkeys. American Journal of Primatology 11: 117-124.

EASLEY, S.P., COELHO, J.A.M. \& TAYLOR, L.L. 1987. Scratching, dominance, tension, and displacement in male baboons. American Journal of Primatology 13: 397-411.

GUST, D.A., GORDON, T.P., HAMBRIGHT, M.K. \& WILSON, M.E. 1993. Relationship between social factors and pituitary adrenocortical activity in female rhesus monkeys (Macaca mulatta). Hormone \& Behaviour 27: 318-331.

KABURU, S.S.K. 2009. Feeding competition among female Barbary macaques (Macaca sylvanus) in the middle atlas mountains of Morocco. MRes Dissertation, Roehampton University. KUTSUKAKE, N. 2003. Assessing relationship quality and social anxiety among wild chimpanzees using self-directed behaviour. Behaviour 140: 1153-1171.

MAESTRIPIERI, D., SCHINO, G., AURELI, F. \& TROISI, A. 1992 (a). A modest proposal:

Displacement activities as an indicator of emotions in primates. Animal Behaviour 44: 967-979.

MAESTRIPIERI, D., MARTEL, F.L., NEVISON, C.M., SIMPSON, M.J.A. \& KEVERNE, E.B. 1992 (b). Anxiety in rhesus monkey infants in relation with their mother and other social companions. Developmental Psychobiology 24: 571-581.

PALAGI, E. \& NORSCIA, I. 2010.Scratching around stress: hierarchy and reconciliation make the 
difference in wild brown lemurs Eulemur fulvus. Stress. doi:DOI: 10.3109/10253890.2010.505272. PAUL, E.S., HARDING, E.J \& MENDL, M. 2005. Measuring emotional processes in animals: the utility of a cognitive approach. Review Neuroscience \& Biobehavioral Reviews 29: 469-491.

PAVANI, S., MAESTRIPIERI, D., SCHINO, G., TURILLAZZI, P.G. \& SCUCCHI, S. 1991. Factors influencing scratching behaviour in long-tailed macaques (Macaca fascicularis). Folia primatologica $57:$ 34-48.

PEIGNOT, P., JANKOWSKI, F. \& ANDERSON, J.R. 2004. On self-scratching in captive mandrills (Mandrillus sphinx). Folia primatologica 75: 160-164.

REDMOND, D.E. \& HUANG, Y.H. 1979. II New evidence for a locus coeruleus norephinephrine connection with anxiety. Life Science 25: 2149-2162.

ROMERO, T., COLMENARES, F. \& AURELI, F. 2009. Testing the function of reconciliation and third-party affiliation for aggressors in Hamadryas baboons (Papio hamandryas hamandryas). American Journal of Primatology 71: 60-69.

SCHINO, G. \& AURELI, F. 2008. Trade-offs in primate grooming reciprocation: testing behavioural flexibility and correlated evolution. Biological Journal of the Linnean Society 95: 439446.

SCHINO, G., SCUCCHI, S., MAESTRIPIERI, D. \& TURILLAZZI, P.G. 1988. Allogrooming as a tension-reduction mechanism: a behavioural approach. American Journal of Primatology 16: 43-50. SCHINO, G., TROISI, A., PERRETTA, G. \& MONACO, V. 1991. Measuring anxiety in nonhuman primates: Effects of lorazepam on macaque scratching. Pharmacology, Biochemistry, and Behavior 38: $889-891$.

SCHINO, G., PERRETTA, G., TAGLIONI, A., MONACO, V. \& TROISI, A. 1996. Primate displacement activities as an ethopharmacological model of anxiety. Anxiety 2: 186-191. SCHINO, G., ROSATI, L., GERMINIANI, S. \& AURELI, F. 2007. Post-conflict anxiety in Japanese macaques (Macaca fuscata): Aggressor's and victim's perspectives. Ethology 113: 10811088. 
TAUB, D.M (1980). Female choice and mating strategies among wild Barbary macaques (Macaca sylvanus L.). In: The macaques: Studies in ecology, behavior and evolution, (ed) D.G. Lindberg, pp 287-344. Van Nostrand Reinhold, New York.

TIEDENS, L.Z. 2000. Powerful emotions: The vicious cycle of social status positions and emotions. In: Emotions in the workplace: Research, theory, and practice, (eds) N. Ashkanasy, W. Zerbe, \& C. Hartel, pp. 71-81. Quorum Books, Westport, CT.

TROISI, A. \& SCHINO, G. (1986). Enviromental and social influences of autogrooming behaviour in a captive group of Java monkeys. Behaviour 100: 292-302.

VENTURA, R., MAJOLO, B., SCHINO, G. \& HARDIE, S. 2005. Differential effects of ambient temperature and humidity on allogrooming, self-grooming, and scratching in wild Japanese macaques. American Journal of Physical Anthropology 126: 453-457

Responsible Editor: J.H. van Wyk 
Table 1. Matrix of the outcome of dyadic conflicts. Females are arranged in rank order, from the highest (AN) to the lowest (NY).

\section{Winner}

\begin{tabular}{lccccccc}
\hline & $\mathbf{A N}$ & $\mathbf{S N}$ & $\mathbf{D E}$ & $\mathbf{L N}$ & $\mathbf{N}$ & $\mathbf{S D}$ & $\mathbf{N Y}$ \\
$\mathbf{A N}$ & $\mathbf{-}$ & 0 & 0 & 0 & 0 & 0 & 0 \\
$\mathbf{S N}$ & 25 & $\mathbf{-}$ & 0 & 0 & 0 & 0 & 0 \\
$\mathbf{D E}$ & 28 & 20 & $\mathbf{-}$ & 0 & 0 & 0 & 0 \\
$\mathbf{L N}$ & 22 & 20 & 36 & $\mathbf{-}$ & 0 & 0 & 0 \\
$\mathbf{N}$ & 37 & 24 & 41 & 22 & $\mathbf{-}$ & 0 & 0 \\
$\mathbf{S D}$ & 32 & 19 & 44 & 44 & 38 & $\mathbf{0}$ & 0 \\
$\mathbf{N Y}$ & 21 & 39 & 29 & 41 & 11 & 11 & $\mathbf{0}$ \\
\hline
\end{tabular}


Table 2. Results of GLMM for relationship between self-scratching rates and rank, aggression and grooming. Significant results shown in bold.

\begin{tabular}{lll}
\hline effect & se & Wald
\end{tabular}

\begin{tabular}{lccccc}
\hline Fixed terms & & & & & \\
rank & $\mathbf{0 . 0 2 6}$ & $\mathbf{0 . 0 0 4}$ & $\mathbf{3 7 . 0 5 0}$ & $<\mathbf{0 . 0 0 1}$ \\
aggression received from adult females & 0.090 & 0.178 & 0.254 & 0.614 \\
aggression given to adult females & $\mathbf{0 . 1 8 6}$ & $\mathbf{0 . 0 7 6}$ & $\mathbf{5 . 9 1 4}$ & $\mathbf{0 . 0 1 5}$ \\
aggression received from adult males & $\mathbf{0 . 2 1 4}$ & $\mathbf{0 . 1 0 6}$ & $\mathbf{4 . 0 4 5}$ & $\mathbf{0 . 0 4 4}$ \\
grooming given to adult males & $\mathbf{0 . 1 6 7}$ & $\mathbf{0 . 0 3 8}$ & $\mathbf{1 9 . 0 2 3}$ & $<\mathbf{0 . 0 0 1}$ \\
grooming received from adult males & $\mathbf{- 0 . 2 0 6}$ & $\mathbf{0 . 0 3 0}$ & $\mathbf{4 6 . 4 4 8}$ & $<\mathbf{0 . 0 0 1}$ \\
grooming given to adult females & 0.051 & 0.058 & 0.773 & 0.379 \\
grooming received from adult females & 0.127 & 0.170 & 0.558 & 0.455 \\
Random terms & & & & \\
individual & & & & \\
\hline day & 0.000 & 0.000 & & \\
\hline
\end{tabular}


Figure 1. Relationship between females' mean rate of self-scratching and dominance rank (1=highest; $7=$ =lowest). $\mathrm{N}=7, \mathrm{r}_{\mathrm{s}}=0.829, \mathrm{p}=0.021$

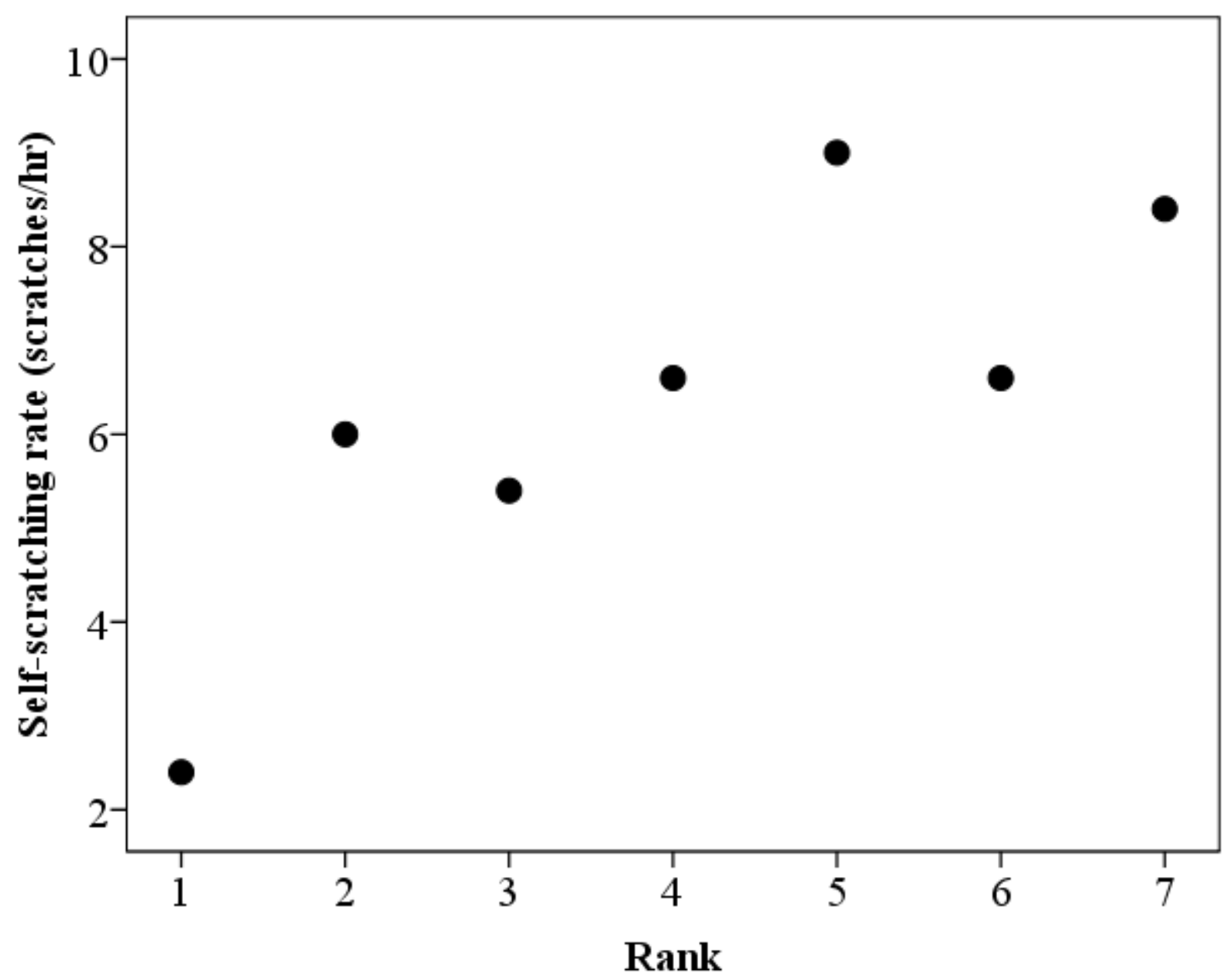

